\title{
Generation of recombinant Chinese hamster ovary cell lines by microinjection
}

\author{
Madiha Derouazi, Rachel Flaction, Philippe Girard, Maria de Jesus, Martin Jordan \& \\ Florian M. Wurm* \\ Laboratory of Cellular Biotechnology, Institute of Biological Engineering and Biotechnology, Ecole \\ Polytechnique Fédérale de Lausanne, Lausanne CH-1015, Switzerland \\ *Author for correspondence (Fax: +41-21-693-6140; E-mail: florian.wurm@epfl.ch)
}

Received 6 October 2005; Revisions requested 27 October 2005; Revisions received 12 December 2005; Accepted 13 December 2005

Key words: calcium phosphate, Chinese hamster ovary cells (CHO), green fluorescent protein (GFP), microinjection, recombinant cell lines

\begin{abstract}
Microinjection is a gene transfer technique enabling partial control of plasmid delivery into the nucleus or cytoplasm of cultured animal cells. Here this method was used to establish various recombinant mammalian cell lines. The injection volume was estimated by fluorescence quantification of injected fluorescein isothyocynate (FITC)-dextran. The DNA concentration and injection pressure were then optimized for microinjection into the nucleus or cytoplasm using a reporter plasmid encoding the green fluorescent protein (GFP). Nuclear microinjection was more sensitive to changes in these two parameters than was cytoplasmic microinjection. Under optimal conditions, $80-90 \%$ of the cells were GFP-positive 1 day after microinjection into the nucleus or the cytoplasm. Recombinant cell lines were recovered following microinjection or calcium phosphate transfection and analyzed for the level and stability of recombinant protein production. In general, the efficiency of recovery of recombinant cell lines and the stability of reporter protein expression over time were higher following microinjection as compared to CaPi transfection. The results demonstrate the feasibility of using microinjection as a method to generate recombinant cell lines.
\end{abstract}

\section{Introduction}

The time consuming and labor intensive process of establishing a recombinant cell line involves the isolation, characterization, and expansion of a clonal cell line from a pool of transfected cells. The most commonly used non-viral transfection methods are calcium phosphate-DNA coprecipitation (CaPi), lipofection, and polyfection (Graham \& Eb 1973, Jordan et al. 1996, Thomas \& Klibanov 2003). All three rely on the formation of positively charged nanoparticles which enter cells after binding to the cell surface. None of these methods, however, allows control of the amount and the subcellular location of the DNA delivered into each individual cell. In contrast, microinjection of plasmid DNA does provide control over these two parameters, and each microinjected cell can be observed and analyzed for early gene expression and cell growth. Microinjection is a common technique for introducing genes into eggs to generate transgenic animals (Brinster et al. 1985). It is also used for gene transfer into cells that are difficult to transfect such as vascular smooth muscle cells and mesenchymal stem cells (Nelson \& Kent 2002, Tsulaia et al. 2003). Furthermore, it has been used to study plasmid DNA degradation, transport, and integration (Folger et al. 1982, Dean 1997, Lechardeur et al. 1999). With Chinese 
hamster ovary (CHO) DG44 cells as the host and green fluorescent protein (GFP) as the reporter, we have investigated several critical parameters of DNA microinjection to evaluate its efficacy for the establishment of recombinant cell lines. The effects of DNA concentration, injection pressure, and the subcellular location of the injection on transgene expression were evaluated. Within 1 month after microinjection, recombinant $\mathrm{CHO}$ cell lines stably expressing GFP were recovered, validating this technique as a potential approach to gene transfer for recombinant cell line generation.

\section{Materials and methods}

\section{Cell culture}

Suspension-adapted CHO DG44 cells (Urlaub et al. 1983) were maintained in serum-free ProCHO5 CDM medium (BioWhittaker Inc., Walkersville, MD) supplemented with $4 \mathrm{~mm}$ glutamine, $0.68 \mathrm{mg} / 1$ hypoxanthine, and $0.194 \mathrm{mg} / 1$ thymidine (HT). The culture was agitated at $120 \mathrm{rpm}$ in square-shaped glass bottles on an orbital shaker in a $37{ }^{\circ} \mathrm{C}$ incubator (Muller et al. 2005).

\section{Plasmids}

The enhanced GFP gene from pEGFP-N1 (Clontech, Palo Alto, CA) was cloned as an EcoRI/ NotI fragment into EcoRI/NotI-digested pMYKEF-1 (kindly provided by Dr Y. S. Kim, Korean Research Institute of Bioscience and Biotechnology) (Kim et al. 2002) to produce pMYKEF1-EGFP. pMYKEF1-EGFP-puro was generated by cloning the puromycin resistance gene as a PvuII/HpaI fragment from pEAK8 (EdgeBiosystems, Gaithersburg, MD) into pMYKEF1-EGFP digested with $B s p \mathrm{H} 1$ and $P v u \mathrm{II}$. pDsRed-Express encoding the red fluorescent protein (RFP) was purchased from Clontech. Plasmid DNA was purified on a Nucleobond®AX anion exchange column (Macherey-Nagel GmbH, Düren, Germany) according to the manufacturers protocol and stored at $1 \mathrm{mg} / \mathrm{ml}$ in water at $-20{ }^{\circ} \mathrm{C}$. For some transfections pMYKEF1-EGFP-puro was linearized by digestion with $P v u \mathrm{I}$ as indicated.

\section{Microinjection}

Microinjection was performed semi-automatically with a FemtoJet (Eppendorf AG, Hamburg, Germany) attached to an InjectMan NI 2 (Eppendorf) mounted on an Axiovert 200M inverted fluorescence microscope (Carl Zeiss AG, Oberkochen, Germany). Femtotips II (Eppendorf) with an inner diameter of $500 \mathrm{~nm}$ and an outer diameter of $700 \mathrm{~nm}$ were used for all injections. Each tip was used for the injection of $20-40$ cells. The injection time was kept constant at the lowest setting possible $(0.1 \mathrm{~s})$, and the injection angle was $45^{\circ}$. A constant compensatory pressure of $30 \mathrm{hPa}$ was applied to the capillary. One day prior to microinjection the cells were transferred to $60 \mathrm{~mm}$ Petri dishes at $5 \times 10^{4}$ cells $/ \mathrm{ml}$ in DMEM/ F12 medium supplemented with HT, $25 \mathrm{~mm}$ HEPES buffer ( $\mathrm{pH} 7.1)$, and $5 \%(\mathrm{v} / \mathrm{v})$ fetal calf serum (FCS). Alternatively, the cells were diluted to 5-10 cells per $20 \mu \mathrm{l}$ in DMEM/F12 medium with $10 \%$ (v/v) FCS, and several $20 \mu$ l droplets were deposited on a $60 \mathrm{~mm}$ Petri dish. After the cells adhered (about 4 h) $4 \mathrm{ml}$ of DMEM/F12 medium supplemented with HT, $10 \% \mathrm{FCS}$, and $25 \mathrm{~mm}$ HEPES buffer ( $\mathrm{pH}$ 7.1) were added to each dish. The latter method was used when cell colonies were to be recovered from the plate. Usually 50-100 cells per dish were injected over a period of 30-45 min at room temperature, and the medium was immediately exchanged with fresh prewarmed DMEM/F12 medium containing either $5 \%$ or $10 \%$ FCS and penicillin (10 000 units $/ \mathrm{ml}$ ), streptomycin $(10 \mathrm{mg} / \mathrm{ml})$, and amphotericin B (25 $\mu \mathrm{g} / \mathrm{ml})$. The percentage of GFP-positive cells was determined 1 day after injection.

\section{Quantification of injection volume}

One hundred and fifty kilodaltons FITC-dextran (Fluka Chemie AG, Buchs, Switzerland) at $5 \mathrm{mg} /$ $\mathrm{ml}$ in water was injected into cells over a range of injection pressures from $70-100 \mathrm{hPa}$. The injection volume was related to the fluorescence based on pixel intensity quantified with LabVIEW IMAQ Vision (National Instruments, Austin, TX). A calibration curve was established by injecting equal volumes having different concentrations of FITC-dextran. Based on linear regression analysis of the standard curve, the injection volume was estimated by injecting cells 
with $0.5 \%$ FITC-dextran. Image acquisition followed the exchange of the medium with phosphate buffered saline (PBS) to avoid interference from medium autofluorescence and FITC-dextran leakage from the capillary. The fluorescence intensity of each individual cell was then quantified using the equation of the standard curve.

\section{Fluorescence microscopy}

Fluorescence was recorded with an AxioCam HR camera mounted on an Axiovert 200M fluorescence microscope (Carl Zeiss AG). FITC and GFP fluorescence were analyzed using a filter with an excitation wavelength of $485 \mathrm{~nm}$ and an emission wavelength of $515-565 \mathrm{~nm}$. Image acquisition was controlled by Axiovision 4.1 software (Carl Zeiss AG). RFP was analyzed using a filter with an excitation wavelength of $545 \mathrm{~nm}$ and an emission wavelength of 605 .

\section{Generation of recombinant cell lines by calcium phosphate transfection}

For transfection with calcium phosphate, an optimized protocol for adherent cells was used (Jordan \& Wurm 2004). Briefly, at $4 \mathrm{~h}$ prior to transfection suspension cells were plated at $4.5 \times 10^{6}$ cells $/ \mathrm{ml}$ in a 12 -well plate in DMEM/ F12. After incubation with the calcium phosphateDNA precipitate at $37^{\circ} \mathrm{C}$ for 3-4 h, the cells were exposed to $10 \%$ glycerol in PBS for $1 \mathrm{~min}$. After removal of the glycerol solution, the cells were washed once with 5 mm EGTA in PBS for $1 \mathrm{~min}$. After removal of the EGTA, pre-warmed DMEM/F12 supplemented with HT and 5\% FBS was added. At two days post-transfection, 1-4 $\times$ $10^{4}$ cells were transferred into a Petri dish and cultivated in DMEM/F12 supplemented with HT, $5 \% \mathrm{FCS}$ and either 3 or $6 \mu \mathrm{g}$ puromycin $/ \mathrm{ml}$. After 10 days colonies of approximately 100 cells were transferred into multi-wells plates and cultivated in the presence of puromycin for 14 weeks.

\section{Generation of recombinant cell lines by microinjection}

Immediately after microinjection, the medium was exchanged with a mixture of pre-conditioned and fresh DMEM/F12 at a ratio of either 1:1 or $1: 3(\mathrm{v} / \mathrm{v})$. FCS was added to a final concentration of $10 \%$. The pre-conditioned DMEM/F12 medium was recovered from a 5-day-old culture of CHO DG44 cells. At day 4 post-microinjection, puromycin was added to give $3 \mu \mathrm{g} / \mathrm{ml}$.

\section{Characterization of recombinant cell lines}

Every 1-2 weeks the specific fluorescence was determined by fluorometry. Cells that had been cultured for 3 days were transferred in $1 \mathrm{ml}$ to a 12-well microtiter plate in DMEM/F12 medium and lysed by addition of $1 \%$ Triton X-100 in PBS. The relative fluorescence was measured with a Cytofluor 4000 plate-reading fluorometer (PerSeptive Biosystems, Farmingham, MA). The excitation wavelength was $485 \mathrm{~nm}$ with a bandwidth of $20 \mathrm{~nm}$, and the emission fluorescence was measured at $530 \mathrm{~nm}$ with a bandwidth of $25 \mathrm{~nm}$. Relative fluorescence units (RFU) were determined by subtraction of the background fluorescence from non-transfected cells. The cell density was assessed with the CASY1 TTC cell counter (Schärfe System GmbH, Reutlingen, Germany). The specific fluorescence corresponded to the relative fluorescence units divided by the number of cells multiplied by 100 .

\section{Results}

\section{Estimation of injection volume}

To study the effect of plasmid copy number on the efficiency of gene delivery by microinjection, it was first necessary to develop an assay to measure the injection volume. The volume is affected by several parameters including the viscosities of both the DNA solution and the recipient cellular compartment as well as the injection time and pressure. Since cellular viscosity cannot be controlled and the injection time in these experiments was kept constant, the injection volume and thus the number of plasmid copies delivered to each cell can be varied either by decreasing the concentration of the DNA or by varying the injection pressure. To estimate the volume of an injection, a solution with a known concentration of $150-\mathrm{kDa}$ FITC-conjugated dextran was injected into cells over a range of injection pressures. This marker was chosen because it cannot 
freely diffuse through nuclear pores, it is not cytotoxic at the concentrations used here, and it is stable for more than $24 \mathrm{~h}$ after injection (Pepperkok et al. 1988). The fluorescence resulting from each injection was then used to estimate the injection volume (Figure 1a-d). Over the range of injection pressures tested $(70-100 \mathrm{hPa})$, the average injection volume in CHO DG44 was found to be 180 femtoliter for nuclear injection and 180-350 femtoliter for cytoplasmic injection (Figure 1e). For injection into the cytoplasm, an increase in the injection pressure resulted in higher injection volumes (Figure 1e). In contrast, no major variation of the injection volume with increasing pressure was observed for microinjection into the nucleus (Figure 1e). Following nuclear injection at $100 \mathrm{hPa}$ a homogenous distribution of FITC-dextran throughout the cell was frequently observed, possibly indicating damage to the nuclear membrane (Figure 1b). The presence of these cells in the microinjected population resulted in a reduction of the upper quartile of the injection volumes (Figure 1e).

\section{Effect of injection pressure and DNA}

concentration on gene transfer efficiency

A successful injection was visible with phasecontrast microscopy as a stream in the nucleus for nuclear injections and as a wave throughout the cell for cytoplasmic injections. An excessive volume change in either the nucleus or the cytoplasm was correlated with a low probability of cell survival. Indeed, microscopic observations of cell volume changes were often accompanied by massive bubbling of the plasma membrane. These cells did not survive beyond 1 day postmicroinjection.

The effect of plasmid copy number on the efficiency of gene transfer by microinjection was determined by injecting cells with various concentrations of pMYKEF1-EGFP-puro ranging from 1.8 to $30 \mu \mathrm{g} / \mathrm{ml}$ at injection pressures that were varied in $10 \mathrm{hPa}$ increments from 70 to $100 \mathrm{hPa}$. This range of pressures was selected because injection at less than $70 \mathrm{hPa}$ yielded little or no DNA transfer into cells and injection at greater than $100 \mathrm{hPa}$ resulted in significant levels of cell damage as described above. For cytoplasmic microinjection the highest efficiency of gene transfer was observed at a DNA concentration of $30 \mu \mathrm{g} / \mathrm{ml}$ over a range of injection pressures from 70 to $90 \mathrm{hPa}$ (Figure 2a). This corresponded to a plasmid copy number of approximately 9000 . Similar results were observed following microinjection of cells at a DNA concentration of $15 \mu \mathrm{g} /$ $\mathrm{ml}$ at pressures from 70 to $80 \mathrm{hPa}$ (Figure 2a). For DNA concentrations lower than $15 \mu \mathrm{g} / \mathrm{ml}$, the efficiency of DNA transfer was lower than $60 \%$ at all injection pressures tested (Figure 2a).
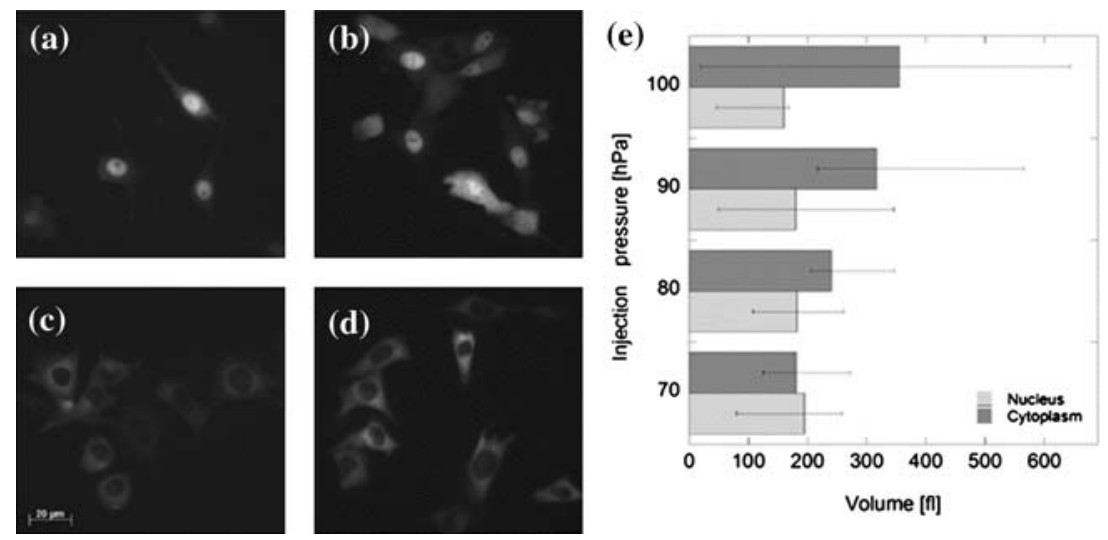

Fig. 1. Analysis of injection volume. CHO DG44 cells were injected in the nucleus (a and b) or the cytoplasm (c and d) with FITC-dextran. The injection pressure was either $70 \mathrm{hPa}$ (a and c) or $100 \mathrm{hPa}(\mathrm{b}$ and d). Images were acquired immediately after microinjection using identical exposure times. The scale bar is equivalent to $20 \mu \mathrm{m}$ and is the same for all the images. (e) Quantification of injection volume by fluorescence measurement after microinjection of FITC-dextran into the nucleus or the cytoplasm. Each bar represents the average of 20-50 injected cells. The upper error bars represent the value for the upper quartile and the lower error bars represent the value for the lower quartile. Thus, between the upper and lower error bars are the fluorescence values for $50 \%$ of the injected cells. 

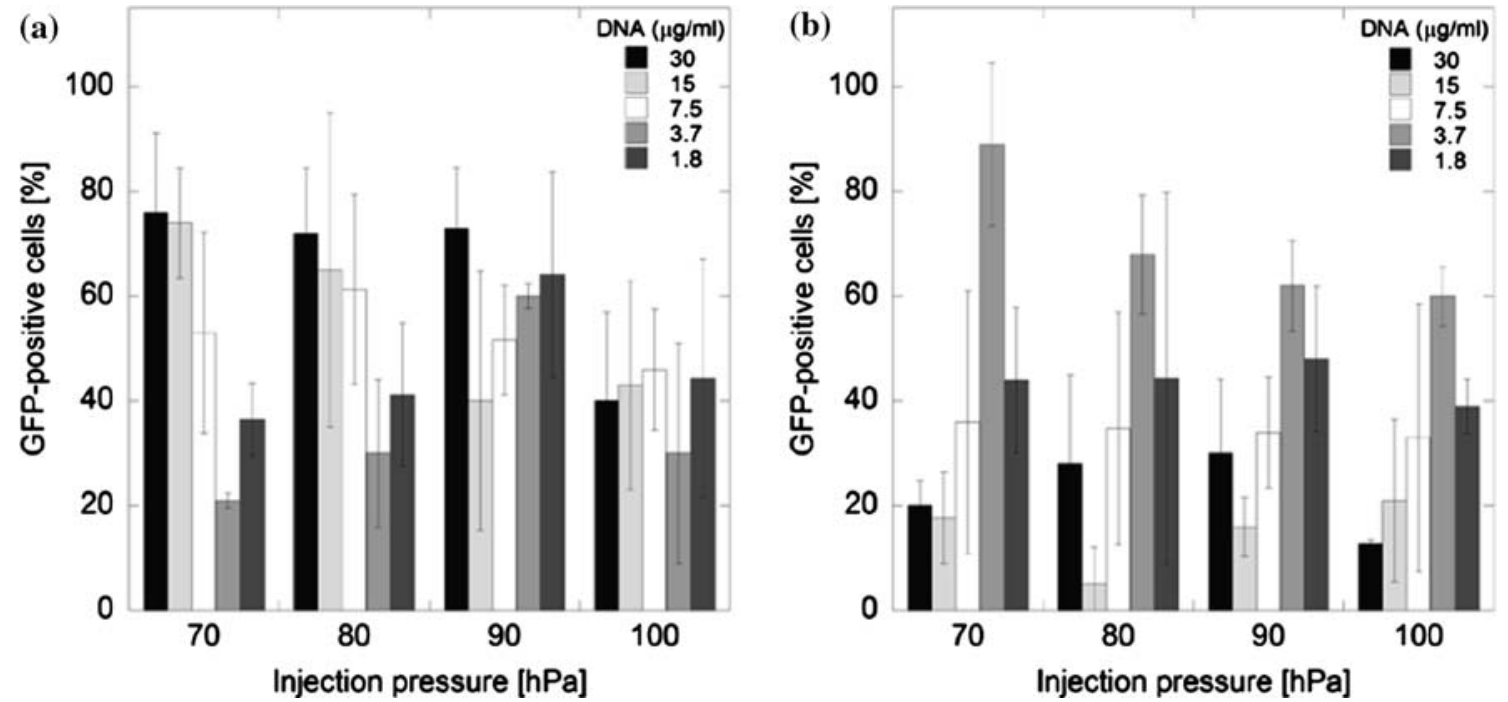

Fig. 2. Microinjection at various DNA concentrations and injection pressures. The cells were injected with pMYKEF1-EGFP-puro in the cytoplasm (a) or the nucleus (b). Cells expressing GFP were counted 1 day after microinjection. Each bar represents the average of four independent experiments each with 25 injected cells.
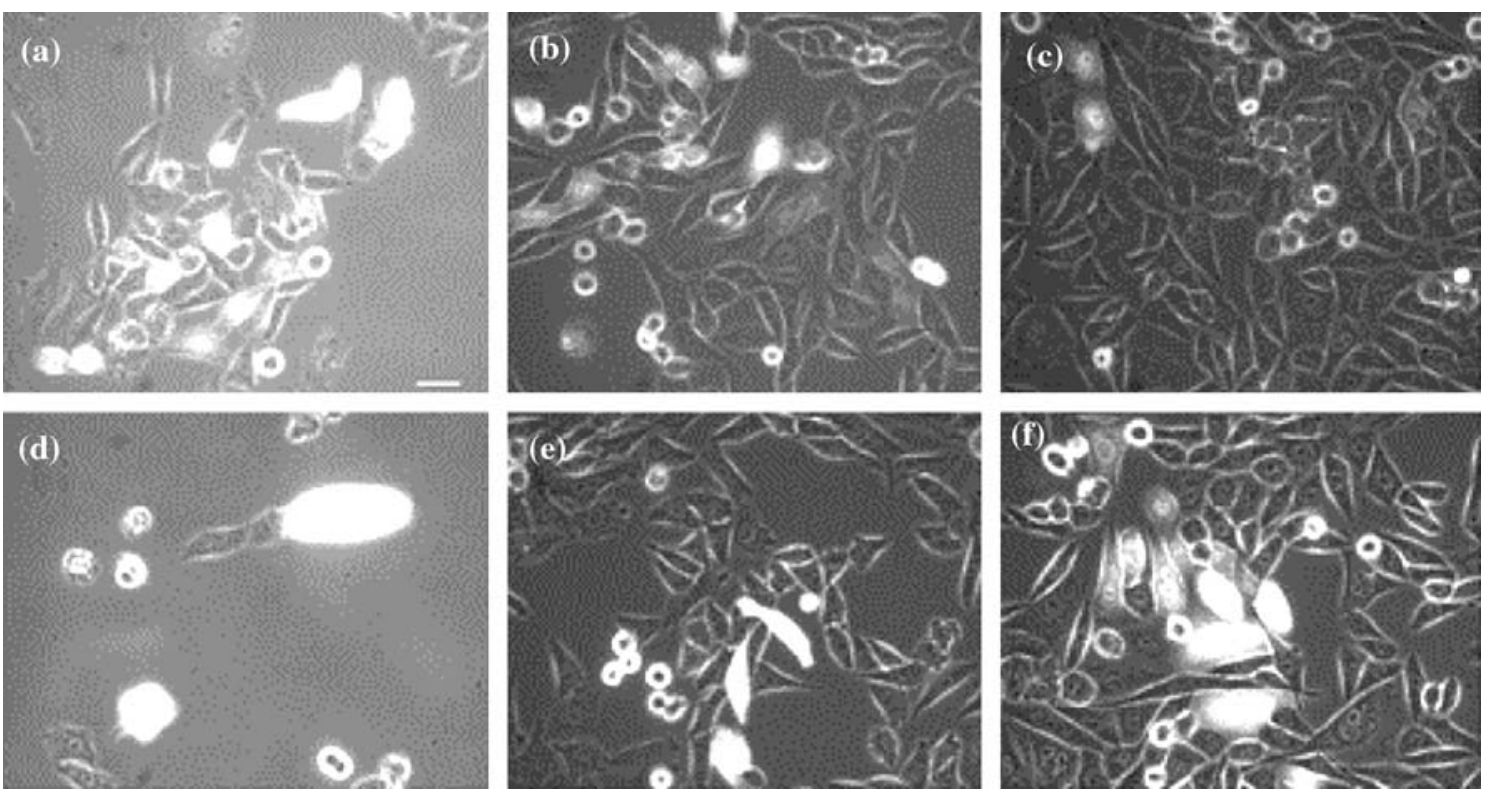

Fig. 3. GFP expression in microinjected cells. The cells were injected in the cytoplasm (top panels) or in the nucleus (bottom panels) with pMYKEF1-EGFP-puro at concentrations of $15 \mu \mathrm{g} / \mathrm{ml}$ (a, d), $7.5 \mu \mathrm{g} / \mathrm{ml}$ (b, e), or $3.7 \mu \mathrm{g} / \mathrm{ml}$ (c, f) and observed after 1 day. The image acquisition time was constant. The scale bar equals $20 \mu \mathrm{m}$ and is the same for all images.

By fluorescence microscopy, it was evident at 1 day after injection that the decrease in the percentage of GFP-positive cells at the lower DNA concentrations was accompanied by a decrease in GFP expression. After cytoplasmic microinjection at DNA concentrations of 7.5 and $15 \mu \mathrm{g} / \mathrm{ml}$ (Figure 3a, b), most of the positive cells were expressing a higher level of GFP than observed following microinjection at a DNA concentration of $3.7 \mu \mathrm{g} / \mathrm{ml}$ (Figure 3c). 
In contrast to the results with cytoplasmic microinjection, the highest DNA transfer efficiency after nuclear microinjection $(90 \%)$ was observed with DNA at $3.7 \mu \mathrm{g} / \mathrm{ml}$ at an injection pressure of $70 \mathrm{hPa}$ (Figure 2b). This corresponded to an injection of about 900 plasmid molecules. In general, the lowest DNA transfer efficiencies resulted from microinjection of the highest concentrations of DNA (15 and $30 \mu \mathrm{g} /$ $\mathrm{ml}$ ) (Figure 2b). GFP-positive cells that were injected with the highest DNA concentrations did not retain the typical cellular morphology and they did not divide (Figure 3d). By reducing the DNA concentration to $7.5 \mu \mathrm{g} / \mathrm{ml}$, the GFP-positive cells retained a more typical morphology (Figure 3e). However, microinjection at this DNA concentration appeared still to have a negative effect on the cell as judged by their rounding and loss of adherence. GFP-positive cells resulting from microinjection at a DNA concentration of $3.7 \mu \mathrm{g} / \mathrm{ml}$ underwent cell division and retained a normal morphology (Figure 3f). In these cells, GFP expression was detected as early as $2 \mathrm{~h}$ post-injection and was higher than that observed following microinjection into the cyto- plasm under any conditions tested (data not shown).

\section{Recombinant protein expression in real time}

Time lapse image acquisition was performed following co-microinjection of cells with $0.5 \%$ FITC-dextran and pDsRed-Express encoding RFP to allow the estimation of the injection volume and the real-time monitoring of recombinant protein expression. As shown in Figure 4, four cells were injected in the nucleus (N1-N4) and one in the cytoplasm (C1) at a DNA concentration of $15 \mu \mathrm{g} / \mathrm{ml}$ with an injection pressure of $70 \mathrm{hPa}$. The cytoplasmic injection resulted in fusion of this cell (C1) with N4. RFP expression in the fused cells was initially observed between 2 and $3 \mathrm{~h}$ post-microinjection (Figure 4, upper right panel). For the other three cells, variations in the injection volume were observed (Figure 4, upper left panel). Surprisingly, for the two cells, which received the lowest amount of FITC-dextran and plasmid (N2 and N3), RFP expression was observed between 1 and $2 \mathrm{~h}$ after microinjection (Figure 4, upper
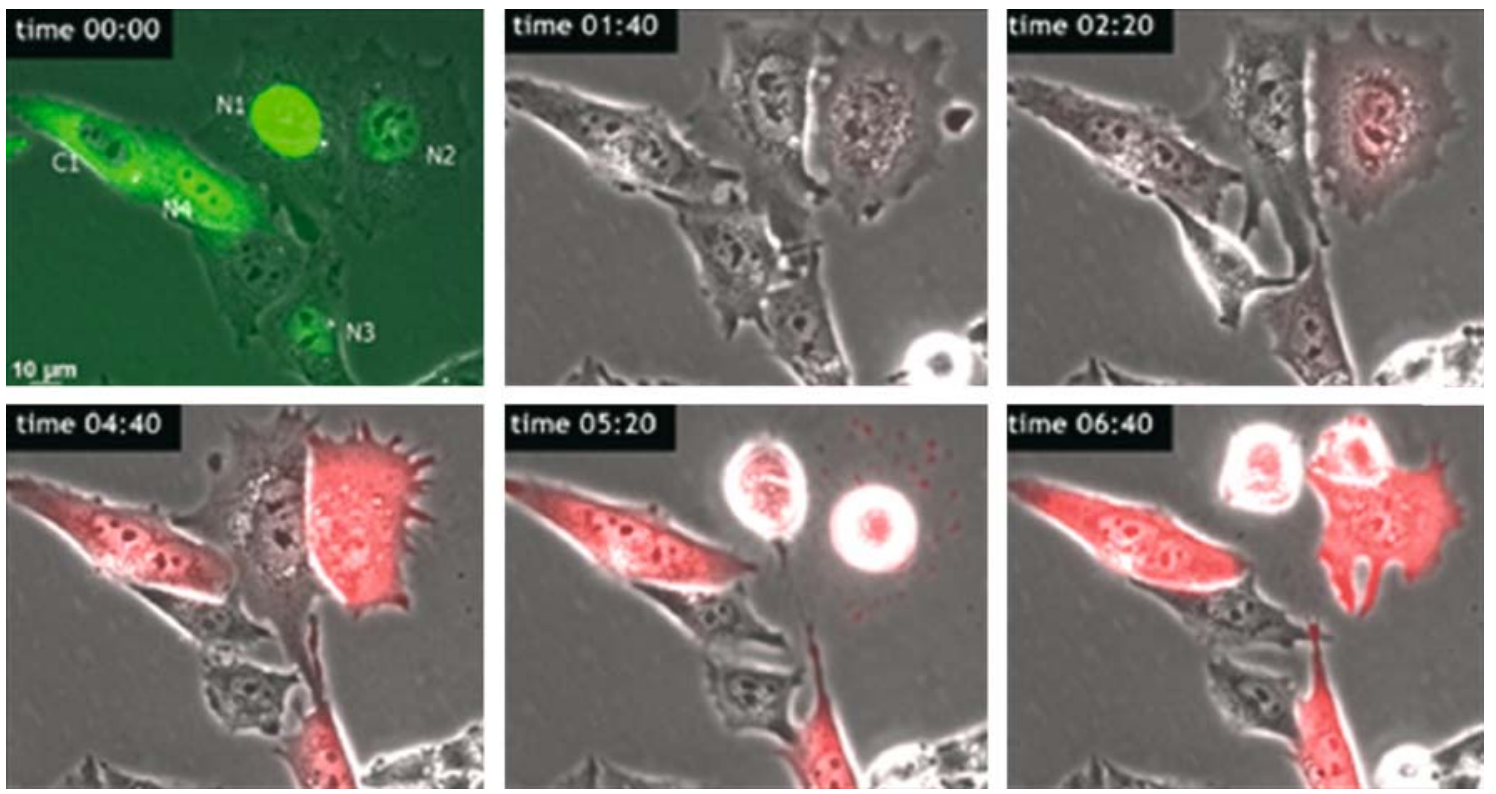

Fig. 4. Time lapse image acquisition after microinjection of cells with $0.5 \%$ FITC-dextran and pDsRed-Express. Cells were microinjected in the nucleus (N) or the cytoplasm (C) (upper left panel). RFP was visualized using the bandpass (BP) Zeiss filter set $\# 43$ (excitation: $545 \mathrm{~nm}$ and BP 25; emission $605 \mathrm{~nm}$ and BP 70). The time post-microinjection is shown in the upper left corner of each image. The exposure time was constant $(100 \mathrm{~ms})$ for each acquisition. The time is reported in hours and minutes. The scale $\operatorname{bar}(10 \mu \mathrm{m})$ is the same for all images. 
middle panel). For the cell injected with the highest amount of FITC-dextran (N1), RFP expression was first observed between 5 to $6 \mathrm{~h}$ after microinjection (Figure 4, lower middle panel). Furthermore, this cell either started to divide but was blocked in mitosis, or was dying (Figure 4, lower right panel). These observations correlate with the results observed in Figure 3. Delivery of a high level of plasmid did not result in a greater number of RFP-positive cells nor in higher recombinant protein expression.

\section{Establishment of recombinant cell lines}

For the establishment of recombinant cell lines, the cells were plated in individual droplets $(20 \mu \mathrm{l})$ each with about 5-10 cells. Only one of the cells originating from each droplet was microinjected with either circular or linear pMYKEF1-EGFPpuro at concentrations of $30 \mu \mathrm{g} / \mathrm{ml}$ in the cytoplasm or $3.7 \mu \mathrm{g} / \mathrm{ml}$ in the nucleus at a pressure of $70 \mathrm{hPa}$. The cells were maintained in the presence of puromycin from day 4 post-microinjection. For nuclear and cytoplasmic microinjection, $47 \%$ and $44 \%$ of the cells, respectively, expressed GFP 1 day after microinjection (Table 1). For most of the GFP-positive cells, fluorescence decreased below the level of detection between 6 and 10 days after microinjection (data not shown). At 8 days post-microinjection, about $13 \%$ of the GFP-positive cells were present as colonies regardless of the subcellular site of microinjection (Table 1). Cells of these colonies were transferred with pipette tips to microtiter plates. By 22 days after microinjection, only four of these remained alive. Thus, the rate of recovery of recombinant cell lines was about $3-4 \%$ for both nuclear and cytoplasmic microinjection (Table 1). The four cell lines were maintained as adherent cultures for 2 months in the absence of puromycin. During this period three of the four showed little variation in the level of specific GFP expression as determined by flow cytometry (data now shown) and fluorometry (Figure 5).

For comparison, CHO DG44 cells were transfected with either circular or linear pMYKEF1EGFP-puro using $\mathrm{CaPi}$, and the cells were exposed to either a low $(3 \mu \mathrm{g} / \mathrm{ml})$ or a high $(6 \mu \mathrm{g} / \mathrm{ml})$ concentration of puromycin. After 10 days of selection, the total number of surviving colonies of greater than 20 cells was determined (Table 2). For three of the four experimental conditions tested, most of the puromycin-resistant colonies did not express a detectable level of GFP as judged by fluorescence microscopy (Table 2). However, almost all of the antibiotic-resistant colonies following transfection with linear pMYKEF1-EGFP-puro and selection in a high concentration of puromycin were fluorescent (Table 2). Overall, the efficiency of recovery of GFP-positive recombinant cell lines following $\mathrm{CaPi}$ transfection was less than that observed for microinjection (Table 2). For each of the four conditions tested for CaPi transfection, the highest GFP producer was maintained in culture without selection pressure for 8 weeks. Three of the four cell lines displayed a progressive decrease of specific GFP expression with time (Figure 6).

\section{Discussion}

Here we have shown the potential for the generation of recombinant cell lines following microinjection of plasmid DNA into the nucleus or

Table 1. Analysis of recombinant cell lines derived by microinjection.

\begin{tabular}{lllllll}
\hline DNA & $\begin{array}{l}\text { Site of } \\
\text { injection }\end{array}$ & No. cells inject. & $\begin{array}{l}\text { a No. GFP-positive } \\
\text { cells }\end{array}$ & $\begin{array}{l}{ }^{b} \text { No. GFP-positive } \\
\text { colonies }(>20 \text { cells) }\end{array}$ & $\begin{array}{l}{ }^{\mathrm{c}} \text { No. recomb. cell lines } \\
\text { cefficiency of line generation }(\%)\end{array}$ \\
\hline Linear & Nucleus & 30 & 16 & 3 & 1 & 3.3 \\
Linear & Nucleus & 25 & 11 & 3 & 1 & 4 \\
Circular & Nucleus & 28 & 12 & 3 & 1 & 3.6 \\
Linear & Cytoplasm & 25 & 11 & 3 & 1 & 4 \\
\hline
\end{tabular}

\footnotetext{
${ }^{\mathrm{a}}$ Determined at 1 day post-microinjection.

${ }^{\mathrm{b}}$ Determined at 8 days post-microinjection (4 days of selection).

${ }^{\mathrm{c}}$ Determined at 22 days post-microinjection (18 days of selection).
} 


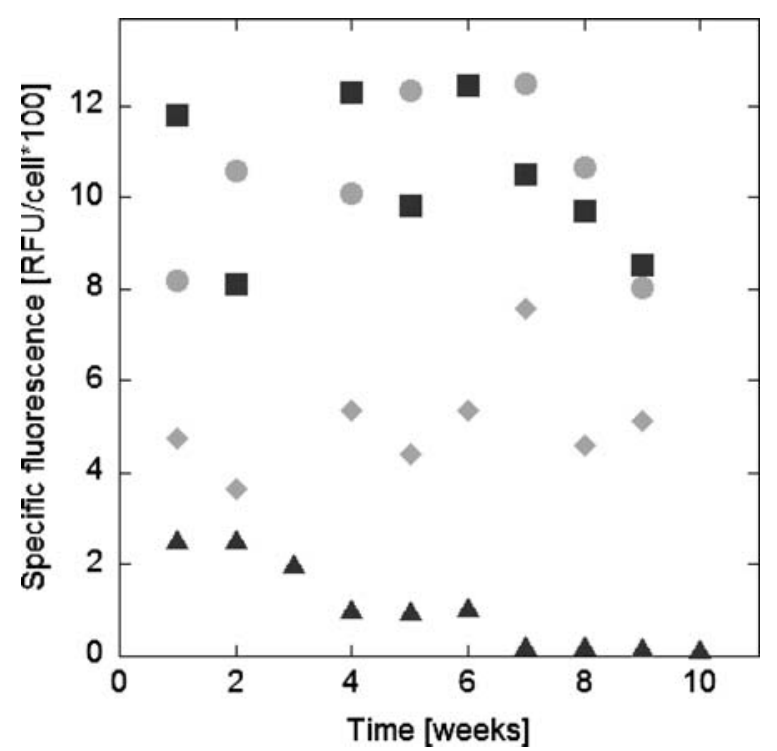

Fig. 5. Cell specific GFP fluorescence of recombinant cell lines established after microinjection. The cell lines were generated by microinjection of linear DNA into the nucleus (and $\mathbf{\Delta})$, circular DNA into the nucleus $(\diamond)$, or linear DNA into the cytoplasm $(\bullet)$.

cytoplasm of CHO DG44 cells. In three of the four cell lines examined over a period of two weeks, recombinant protein expression was stable. The time necessary to generate a cell line was 3-4 weeks from the time of microinjection. This was more rapid than has typically been observed for the recovery of recombinant cell lines following DNA transfection (usually 5-8 weeks). Thus, microinjection appears to be a promising approach for the rapid establishment of recombinant cell lines. However, further comparisons need to be made among the various gene delivery methods to verify the efficiency of recombinant cell line recovery.
As a general rule, we observed that the concentration of DNA injected into cells had a dramatic impact on the gene transfer efficiency and the reporter protein expression level. For cytoplasmic microinjection, the highest percentage of GFP-positive cells and the highest level of GFP expression were achieved with a DNA concentration of $30 \mu \mathrm{g} / \mathrm{ml}$. In contrast, the most successful nuclear injections were executed with a 10-fold lower DNA concentration. One major difference between the two subcellular sites of injection is that DNA introduced into the nucleus is immediately available for transcription whereas DNA introduced into the cytoplasm must first be transported into the nucleus. Three main factors affect DNA transport into the nucleus. Cytoplasmic DNA is subject to enzymatic degradation (Lechardeur et al. 1999, Pollard et al. 2001). However, increasing the level of cytoplasmic DNA may saturate the nucleases (Pollard et al. 2001). Second, transport of DNA into the nucleus may take place only during mitosis after the breakdown of the nuclear membrane (Brunner et al. 2000, Grosjean et al. 2002). Lastly, active transport of the DNA from the cytoplasm to the nucleus via interactions with DNA binding proteins targeted to the nucleus may be necessary as discussed in more detail below (Dean 1997).

One recombinant cell line was established after cytoplasmic microinjection of plasmid DNA. This was an important observation since it was technically easier to inject DNA into the cytoplasm than the nucleus. Others have reported an absence of reporter gene expression in either mouse or human cells after microinjection into the cytoplasm (Capecchi 1980, Mirzayans et al. 1992). However, binding of transcription factors to the promoter of a mammalian expression

Table 2. Analysis of recombinant cell lines derived by calcium phosphate transfection.

\begin{tabular}{llllcl}
\hline DNA & $\begin{array}{l}\text { Puromycin } \\
{[\mu \mathrm{g} / \mathrm{ml}]}\end{array}$ & $\begin{array}{l}\text { No. cells } \\
\text { selected }\end{array}$ & $\begin{array}{l}{ }^{\mathrm{a}} \text { No. } \\
\text { colonies }\end{array}$ & $\begin{array}{l}{ }^{\mathrm{a}} \text { No. GFP-positive } \\
\text { colonies }(>20 \text { cells) }\end{array}$ & $\begin{array}{l}{ }^{\mathrm{b}} \text { Efficiency of } \\
\text { cell line } \\
\text { generation }(\%)\end{array}$ \\
\hline Circular & 3 & 10000 & 1000 & 57 & 0.6 \\
Circular & 6 & 20000 & 2000 & 100 & 0.5 \\
Linear & 3 & 20000 & 1900 & 39 & 0.2 \\
Linear & 6 & 40000 & 700 & 627 & 1.5 \\
\hline
\end{tabular}

\footnotetext{
${ }^{a}$ Determined after 10-11 days of selection.

${ }^{\mathrm{b}}$ Based on the number of GFP-positive colonies.
} 


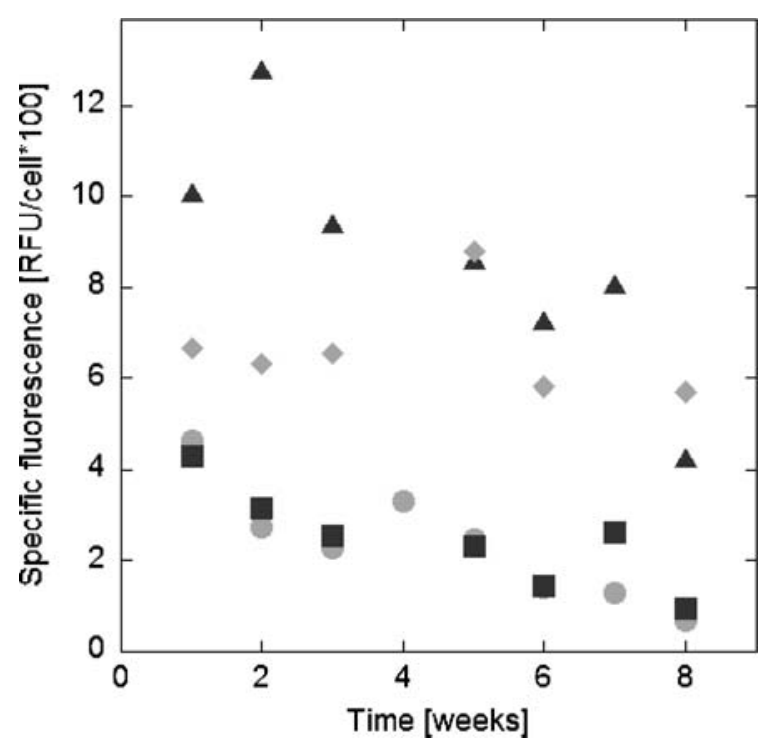

Fig. 6. Cell specific GFP fluorescence of recombinant cell lines after $\mathrm{CaPi}$ transfection. The cell lines were generated by transfection of circular $(\bullet$ and $\boldsymbol{\square})$ or linear DNA $(\boldsymbol{\Delta}$ and $\diamond)$ and isolated after selection with either $3(\boldsymbol{\square}$ and $\diamond)$ or $6(\bullet$ or A) $\mu$ g puromycin $/ \mathrm{ml}$.

vector may greatly facilitate transport of the plasmid DNA from the cytoplasm to the nucleus (Dean 1997, Vacik et al. 1999). pMYKEF1EGFP-puro carries both the murine cytomegalovirus major immediate early promoter and the human herpes simplex virus thymidine kinase promoter. It is possible that either one or both of these DNA elements may have facilitated the transport of the plasmid to the nucleus.

For the determination of the plasmid copy number during microinjection, we developed a fluorescence based quantification of the injection volume. Possibly due to viscosity differences among individual cells, the injection volume varied up to two-fold even under the same conditions of injection time and pressure. With our approach we were able to estimate the variation of the injection volume from one cell to another. However, we observed that under otherwise identical conditions, the volume for nuclear injections was less than that for cytoplasm injections. This was assumed to be due to a higher viscosity in the nucleus than in the cytoplasm.

The droplet method used for plating cells prior to microinjection presented several advantages. It was easier to identify the cell to be injected, and the cell density was low enough to avoid overgrowth of the injected cells by the non-injected cells. Since only one cell was injected in each droplet, the GFP-positive colonies were not mixed with other injected cells. The main difficulty in this approach was the initiation of cell growth after injection. This problem was solved by the addition of conditioned medium derived from 5-day-old CHO DG44 cell cultures.

The efficiency of stable transfection or stable cell line recovery is a matter of definition. This value was easier to determine for microinjection than for CaPi-mediated transfection since the number of cells injected was known and each injected cell was analyzed for GFP expression. By considering the number of colonies resulting from each $\mathrm{CaPi}$ transfection, we determined the efficiency of stable transfection to be around $10 \%$. However, since the recombinant protein (GFP) was visually detectable, we could redefine the stable transfection efficiency as the percentage of GFP-positive colonies in the population of transfected cells. In this case, the number was typically 10 times lower than the total number of colonies surviving selection in puromycin for 10 days. When considering only GFP-positive colonies, we observed 3-6 fold higher stable transfection efficiency by microinjection as compared to CaPi-mediated transfection. Furthermore, in our cell lines we observed a more stable recombinant protein production after microinjection than after CaPi transfection. Thus, microinjection may be an interesting approach to quickly isolate recombinant cell lines stably expressing high levels of protein product.

In conclusion, microinjection appears to be a promising gene transfer method for the establishment of recombinant mammalian cell lines. Besides controlling the amount and subcellular location of DNA delivery, microinjection also allows the co-delivery of enzymes such as DNA recombinases (Bode et al. 2000), viral DNA integrases (Tanaka \& Komuro 2005) or even restriction enzymes (Manivasakam et al. 2001) to enhance the probability of exogenous DNA integration into the host genome.

\section{Acknowledgements}

We thank Dr David Hacker for critically reading the manuscript. We thank Dr Claudio 
Denoya for his advice. This work was supported by Pfizer Inc.

\section{References}

Bode J, Schlake T, Iber M, Schubeler D, Seibler J, Snezhkov E, Nikolaev L (2000) The transgeneticist's toolbox: novel methods for the targeted modification of eukaryotic genomes. Biol. Chem. 381: 801-813.

Brinster RL, Chen HY, Trumbauer ME, Yagle MK, Palmiter RD (1985) Factors affecting the efficiency of introducing foreign DNA into mice by microinjecting eggs. Proc. Natl. Acad. Sci. 82: 4438-4442.

Brunner S, Sauer T, Carotta S, Cotten M, Saltik M, Wagner E (2000) Cell cycle dependence of gene transfer by liploplex, polyplex and recombinant adenovirus. Gene Ther. 7: 401-407.

Capecchi MR (1980) High efficiency transformation by direct microinjection of DNA into cultured mammalian cells. Cell 22: 479-488.

Dean DA (1997) Import of plasmid DNA into the nucleus is sequence specific. Exp. Cell Res. 230: 293-302.

Folger KR, Wong EA, Wahl G, Capecchi MR (1982) Patterns of integration of DNA microinjected into cultured mammalian cells: evidence for homologous recombination between injected plasmid DNA molecules. Mol. Cell Biol. 2: 1372-1387.

Graham FL, Eb AJ van der (1973) A new technique for the essay of the infectivity of human adenovirus 5 DNA. Virology 52: 456-467.

Grosjean F, Batard P, Jordan M, Wurm F (2002) S-phase synchronized $\mathrm{CHO}$ cells show elevated transfection efficiency and expression using CaPi. Cytotechnology 38: 57-62.

Jordan M, Schallhorn A, Wurm FM (1996) Transfecting mammalian cells: optimization of critical parameters affecting calcium phosphate precipitate formation. Nucleic Acids Res. 24: 596-601.

Jordan M, Wurm F (2004) Transfection of adherent and suspended cells by calcium phosphate. Methods 33: 136-143.

Kim SY, Lee JH, Shin HS, Kang HJ, Kim YS (2002) The human elongation factor 1 alpha (EF-1 alpha) first intron highly enhances expression of foreign genes from the murine cytomegalovirus promoter. J. Biotechnol. 93: 183-187.

Lechardeur D, Sohn KJ, Haardt M, Joshi PB, Monck M, Graham RW, Beatty B, Squire J, O'Brodovich H, Lukacs GL (1999) Metabolic instability of plasmid DNA in the cytosol: a potential barrier to gene transfer. Gene Ther. 6: 482-497.

Manivasakam P, Aubrecht J, Sidhom S, Schiestl RH (2001) Restriction enzymes increase efficiencies of illegitimate DNA integration but decrease homologous integration in mammalian cells. Nucleic Acids Res. 29: 4826-4833.

Mirzayans R, Aubin RA, Paterson MC (1992) Differential expression and stability of foreign genes introduced into human fibroblasts by nuclear versus cytoplasmic microinjection. Mutat. Res. 281: 115-122.

Muller N, Girard P, Hacker DL, Jordan M, Wurm FM (2005) Orbital shaker technology for the cultivation of mammalian cells in suspension. Biotechnol. Bioeng. 89: 400-406.

Nelson PR, Kent KC (2002) Microinjection of DNA into the nuclei of human vascular smooth muscle cells. J. Surg. Res. 106: 202-208.

Pepperkok R, Schneider C, Philipson L, Ansorge W (1988) Single cell assay with an automated capillary microinjection system. Exp. Cell Res. 178: 369-376.

Pollard H, Toumaniantz G, Amos JL, Avet-Loiseau H, Guihard G, Behr JP, Escande D (2001) $\mathrm{Ca}^{2+}$-sensitive cytosolic nucleases prevent efficient delivery to the nucleus of injected plasmids. J. Gene Med. 3: 153-164.

Tanaka AS, Komuro K (2005) Targeted rearrangement of a chromosomal repeat sequence by transfection of a homologous DNA sequence using purified integrase. Gene Ther. 12: 783-794.

Thomas M, Klibanov AM (2003) Non-viral gene therapy: polycation-mediated DNA delivery. Appl. Microbiol. Biotechnol. 62: 27-34.

Tsulaia TV, Prokopishyn NL, Yao A, Carsrud ND, Carou MC, Brown DB, Davis BR, Yannariello-Brown J (2003) Glass needle-mediated microinjection of macromolecules and transgenes into primary human mesenchymal stem cells. J. Biomed. Sci. 10: 328-336.

Urlaub G, Kas E, Carothers AM, Chasin LA (1983) Deletion of the diploid dihydrofolate reductase locus from cultured mammalian cells. Cell 33: 405-412.

Vacik J, Dean BS, Zimmer WE, Dean DA (1999) Cell-specific nuclear import of plasmid DNA. Gene Ther. 6: 1006-1014. 